\title{
Network reconfiguration and loss allocation in a deregulated environment of distribution systems
}

DOI:

10.1049/cp:20051258

Link to publication record in Manchester Research Explorer

\section{Citation for published version (APA):}

Oliveira, M. E., Ochoa, L. F., Padilha-Feltrin, A., \& Mantovani, J. R. S. (2005). Network reconfiguration and loss allocation in a deregulated environment of distribution systems. In IEE Conference Publication/IEE Conf Publ (Vol. 4, pp. 303-306) https://doi.org/10.1049/cp:20051258

\section{Published in:}

IEE Conference Publication|IEE Conf Publ

\section{Citing this paper}

Please note that where the full-text provided on Manchester Research Explorer is the Author Accepted Manuscript or Proof version this may differ from the final Published version. If citing, it is advised that you check and use the publisher's definitive version.

\section{General rights}

Copyright and moral rights for the publications made accessible in the Research Explorer are retained by the authors and/or other copyright owners and it is a condition of accessing publications that users recognise and abide by the legal requirements associated with these rights.

\section{Takedown policy}

If you believe that this document breaches copyright please refer to the University of Manchester's Takedown Procedures [http://man.ac.uk/04Y6Bo] or contact uml.scholarlycommunications@manchester.ac.uk providing relevant details, so we can investigate your claim.

\section{OPEN ACCESS}




\section{NETWORK RECONFIGURATION AND LOSS ALLOCATION IN A DEREGULATED ENVIRONMENT OF DISTRIBUTION SYSTEMS \\ Marcelo E. OLIVEIRA*, Luis F. OCHOA*†, Antonio PADILHA-FELTRIN*, José R. S. MANTOVANI* \\ * UNESP - Universidade Estadual Paulista, Campus de Ilha Solteira - Brazil \\ $\dagger$ University of Edinburgh, School of Engineering and Electronics - United Kingdom escobar@dee.feis.unesp.br, luis_ochoa@ieee.org, padilha@dee.feis.unesp.br, mant@dee.feis.unesp.br}

\section{SUMMARY}

Low flexibility and reliability in the operation of radial distribution networks make those systems be constructed with extra equipment as sectionalising switches in order to reconfigure the network, so the operation quality of the network can be improved. Thus, sectionalising switches are used for fault isolation and for configuration management (reconfiguration).

Moreover, distribution systems are being impacted by the increasing insertion of distributed generators. Hence, distributed generation became one of the relevant parameters in the evaluation of systems reconfiguration. Distributed generation may affect distribution networks operation in various ways, causing noticeable impacts depending on its location. Thus, the loss allocation problem becomes more important considering the possibility of open access to the distribution networks.

In this work, a graphic simulator for distribution networks with reconfiguration and loss allocation functions, is presented. Reconfiguration problem is solved through a heuristic methodology, using a robust power flow algorithm based on the current summation backward-forward technique, considering distributed generation. Four different loss allocation methods (Zbus, Direct Loss Coefficient, Substitution and Marginal Loss Coefficient) are implemented and compared. Results for a 32-bus medium voltage distribution network, are presented and discussed.

\section{SIMULATOR}

Due to the complexity of distribution systems planning, operation and analysis, it is very important to develop tools for helping engineers, training utilities' staff and teaching engineering students. Computational programs without visual interfaces are suitable for specialised engineers and technicians since require an extra effort for interpreting (or visualise) results. Consequently, those programs could not be used for training purposes.

Various simulators have appeared for transmission networks analysis and training, but very few for distribution. This work presents a distribution networks simulator which has a visual interface based on Visual Basic in order to visualise feeders reconfiguration and loss allocation considering networks with distributed generators. Figure 1 shows the general structure of the proposed simulator.

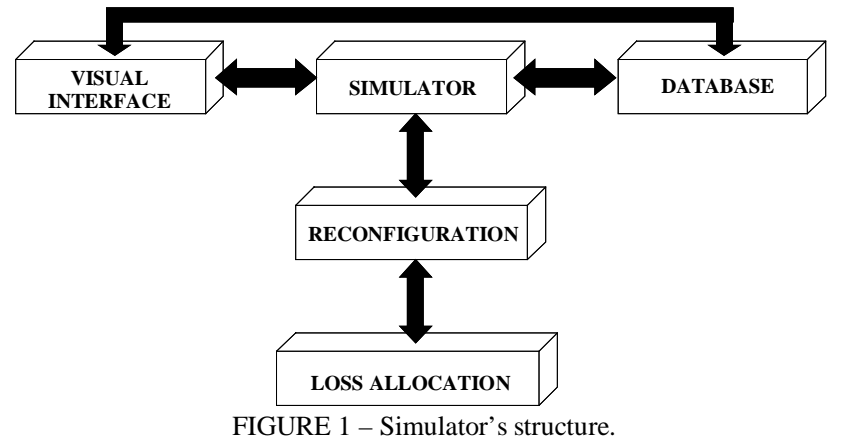

The visual interface allows visualising results obtained from simulations and distribution network topology, and updating (or modifying) the database which contains all the analysed system data. Network reconfiguration is performed with a decision tree-search heuristic technique which finds 5 configurations with the smallest values of total power losses, considering system's energy quality and reliability constraints. This technique utilises a current summation power flow algorithm adapted to distribution networks with distributed generation (DG). Loss allocation is aimed at attributing responsibilities to consumers and generators' impacts on total power losses.

\section{RECONFIGURATION}

Reconfiguration problem can be formulated as follows:

$$
\operatorname{Min} P_{k}=\sum_{L=1}^{N R} R_{L} \cdot I_{L}^{2}
$$

subject to:

- radiality;

- voltage level constraints;

- reliability constraints;

- load balancing between feeders constraints;

- integer and continuos variables.

where: $L \in \mathrm{I}$, I is the set of all branches in the system; $k \in \mathrm{K}, \mathrm{K}$ is the set of all radial feasible configurations for the system; $N R$ is the number of branches for configuration $k$.

For solving the reconfiguration problem it was developed a heuristic methodology that considers constraints from (1) and uses a criterion for cutting poor quality configurations. This criterion is based on the maximum voltage drop allowed in the feeders, in order to identify promissory configurations regarding 
minimal losses and constraints from (1). Therefore, the selection of configuration will be performed based on this value, i.e. if a configuration presents a voltage drop greater than a specified limit, then any configuration generated from that one will be neglected.

Implemented algorithm identifies the initial configuration from two sets of closed and opened sectionalising switches. Initial configuration appears at the level $n_{0}$ of the decision tree, and each set of configurations generated by closing an opened switch forms another level. In this way, closing the first switch the level $n_{l}$ of the tree is formed with a set of configurations generated from the previous level (in this case, only level $n_{0}$ ). When closing the second switch, all configurations of previous levels $\left(n_{0}\right.$ and $\left.n_{l}\right)$ will be used to generate configuration for level $n_{2}$. This process is repeated until all opened switches from the initial configuration are closed. In the decision tree, the number of levels will be equal to the number of sectionalising switches in the system. At each level there will be the most attractive configurations which will remain active for generating other configurations in subsequent levels. Non-attractive configurations will be neglected as soon they are found.

\section{Power Flow Algorithm}

Current summation backward-forward method [1] is applied for solving weakly meshed or radial distribution networks power flow. DG can be modelled as a PQ or PV bus. In the former case there is no need to modify the power flow formulation, however in the latter some special procedures should be performed in order to maintain voltage and reactive power within specified values.

\section{LOSS ALLOCATION}

\section{Zbus Method}

The Zbus method [2] considers system's total losses as the sum of all line losses, according the following equation:

$L=\frac{1}{2} \sum_{k=1}^{n} \sum_{m=1}^{n} G_{k m}\left[V_{k}^{2}+V_{m}^{2}-2 V_{k} V_{m} \cos \left(\theta_{k}-\theta_{m}\right)\right]$

Here, losses are allocated by coupling current injection at node $i$ with currents of the other $n$ buses of the system. Network's topology is also considered when using (3):

$$
L_{i}=\mathfrak{R}\left\{I_{i}^{*}\left(\sum_{j=1}^{n} R_{i j} I_{j}\right)\right\}
$$

where: $R_{i j}$ is the resistance matrix of the system.

It is important to notice that admittance matrix ( $\mathrm{Y}_{\mathrm{BUS}}$ ), is singular when distribution systems are analysed, since capacitive lines effects are neglected. In transmission systems the slack bus is considered and should pay for its losses. In the other hand, in distribution systems there are no losses allocated to the slack bus (substation). Therefore, neglecting the slack bus in the admittance matrix, loss allocation can be obtained by using its inverse: impedance matrix $\mathrm{Z}_{\mathrm{BUS}}$. This consideration does not affect neither the fair loss allocation nor the computation of the total losses.

\section{Substitution Method (SM)}

Also know as the electric circuits compensation theorem, the substitution method compares total losses with those losses computed disconnecting each node of the system [3]. In this way, the system is divided in $n$ (number of nodes) subsystems in which total losses are calculated neglecting power injection (load or generator) for the analysed node. Difference between original system's total losses and a subsystem's total losses (related to node $i$ ), multiplied by a correction factor $\left(f_{C}\right)$, corresponds to the losses produced by node $i$ :

$$
\begin{gathered}
L_{i}=f_{C} \cdot\left(P_{\text {total }}^{n}-P_{i}^{\text {total }}\right) \\
f_{C}=\frac{P_{\text {total }}^{n}}{\sum_{i=1}^{n} P_{i}^{\text {total }}}
\end{gathered}
$$

where: $P^{n}$ total represents total losses of the original system (n nodes); $P_{i}^{\text {total }}$ represents total losses of the subsystem analysing node $i$ (null load or generation). Correction factor is required due to the system's non-linearities, i.e. sum of obtained loss allocation for each node is not equivalent to the system's total losses.

\section{Marginal Loss Coefficient (MLC)}

This method reflects loss sensitivity related to the power injection variation (real $P_{i}$ and reactive $Q_{i}$ ) at each node $i$ of the system [3]. Firstly, it determines a marginal factor called $\tilde{\rho}$ for each node $i$ of the network.

$$
\tilde{\rho}_{P_{i}}=\left[\frac{\partial L}{\partial P_{i}}\right] \quad \text { and } \quad \tilde{\rho}_{Q_{i}}=\left[\frac{\partial L}{\partial Q_{i}}\right]
$$

where: $L$ represents total real power losses; $\tilde{\rho}_{P_{i}}$ is the real factor of MLC for node $i$; $\tilde{\rho}_{Q_{i}}$ is the reactive factor of MLC, for node $i$.

The factors $\tilde{\rho}$ are obtained as showed in [3], and the loss allocation for bus $i$ is:

$$
L^{\prime}=\tilde{\rho}_{P_{i}} P_{i}+\tilde{\rho}_{Q_{i}} Q_{i}
$$


However, since $\sum L_{i}^{\prime}=2 L$, it is necessary an adjustment factor $f_{C}$ (according to the substitution method), in order to obtain a new marginal factor $(\rho)$ :

$$
\rho=f_{C} \times \tilde{\rho}
$$

Finally, loss allocation for each bus $i$ is obtained:

$$
L=\rho_{P_{i}} \times P_{i}+\rho_{Q_{i}} \times Q_{i}
$$

\section{Direct Loss Coefficient (DLC)}

This method is aimed at directly relating losses to the nodal injection, without requiring an adjustment [4]. For a given change in the operating point, losses can be computed using expansion on Taylor's series around an initial operating point. Position of the new loss is given by (18), and its expanded form by (19):

$$
\begin{gathered}
L \cong f\left(\theta^{0}+\Delta \theta, V^{0}+\Delta V\right) \\
L \cong f\left(\theta^{0}, V^{0}\right)+\left[\begin{array}{ll}
\Delta \theta & \Delta V
\end{array}\right]\left[\begin{array}{l}
\frac{\partial L}{\partial \theta} \\
\frac{\partial L}{\partial V}
\end{array}\right]+ \\
+\frac{1}{2}\left[\begin{array}{ll}
\Delta \theta & \Delta V
\end{array}\right][H]\left[\begin{array}{c}
\Delta \theta \\
\Delta V
\end{array}\right]+\ldots
\end{gathered}
$$

where: $\Delta \theta$ and $\Delta V$ are variations between values after convergence and initialisation; $H$ is the Hessian matrix, second order derivative of (2) related to state variables.

Since at the initialisation there is no power flow through the circuit, losses can be obtained as follows [4]:

$$
L \cong \frac{1}{2}\left[\begin{array}{ll}
\Delta \theta & \Delta V
\end{array}\right][H]\left[\frac{1}{2}\left(J^{0}+J\right)\right]\left[\begin{array}{l}
P \\
Q
\end{array}\right]
$$

Thus, the factor of direct losses $\gamma$ is:

$$
\gamma=\left[\begin{array}{l}
\gamma_{P} \\
\gamma_{Q}
\end{array}\right] \cong \frac{1}{2}\left[\begin{array}{ll}
\Delta \theta & \Delta V
\end{array}\right][H][\bar{J}]^{-1}
$$

Therefore, considering $\gamma_{P i}$ and $\gamma_{Q i}$ as the real and reactive parts, respectively, for the factor at bus $i$, loss allocation is given by:

$$
L_{i}=\gamma_{P i} \times P_{i}+\gamma_{Q i} \times Q_{i}
$$

Figure 2 shows the initial configuration of the 32-bus system (output of the developed simulator). This system has 5 opened sectionalising switches between buses 7-20, 8-14, 11-21, 17-32 and 24-28. Full system data can be found in [5]. Total losses for the original configuration is $176.36 \mathrm{~kW}$.

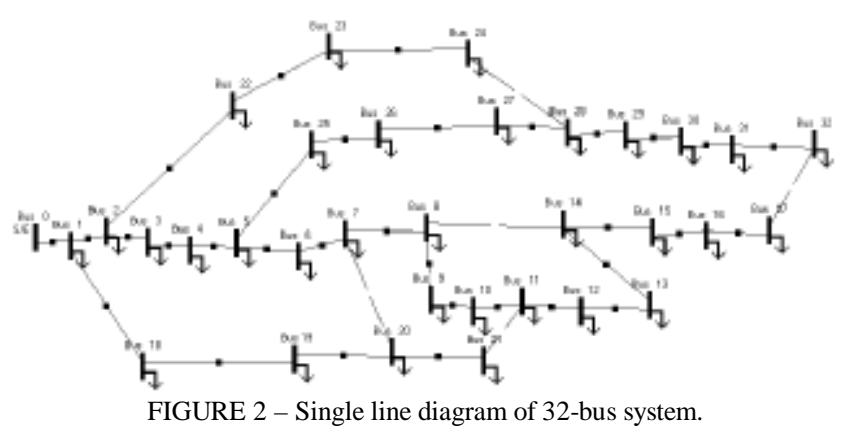

The simulator gives as result the top 5 configurations with the lowest losses of the analysed system. Voltage levels and loss allocation for each bus are presented as attached results for each obtained configuration. Utilised distributed generator power output is $930 \mathrm{~kW}$ with unity power factor. Table 1 and Table 2 show the top 5 configurations with their values of total losses, considering ant not the insertion of DG, respectively.

TABLE 1 - Top 5 Configurations for the 32-bus system without Distributed

\begin{tabular}{c|c|c}
\multicolumn{3}{|c}{ Generation. } \\
\hline \multirow{2}{*}{ Config. } & without DG \\
\cline { 2 - 3 } & Open Switches & Losses (kW) \\
\hline 1 & $6-7 / 13-14 / 8-9 / 31-32 / 24-28$ & 127.36 \\
\hline 2 & $6-7 / 13-14 / 8-9 / 31-32 / 27-28$ & 127.84 \\
\hline 3 & $6-7 / 13-14 / 9-10 / 31-32 / 24-28$ & 127.95 \\
\hline 4 & $6-7 / 13-14 / 9-10 / 31-32 / 27-28$ & 128.44 \\
\hline 5 & $6-7 / 13-14 / 10-11 / 31-32 / 24-28$ & 128.71 \\
\hline
\end{tabular}

TABLE 2 - Top 5 Configurations for the 32-bus system with Distributed

\begin{tabular}{c|c|c}
\multicolumn{3}{|c}{ Generation. } \\
\hline \multirow{2}{*}{ Config. } & \multicolumn{2}{|c}{ with DG (Bus 23) } \\
\cline { 2 - 3 } & Open Switches & Losses (kW) \\
\hline 1 & $6-7 / 13-14 / 8-9 / 31-32 / 27-28$ & 96.76 \\
\hline 2 & $6-7 / 13-14 / 8-9 / 17-32 / 27-28$ & 96.96 \\
\hline 3 & $7-20 / 13-14 / 8-9 / 31-32 / 27-28$ & 97.31 \\
\hline 4 & $6-7 / 13-14 / 9-10 / 31-32 / 27-28$ & 97.36 \\
\hline 5 & $6-7 / 13-14 / 9-10 / 17-32 / 27-28$ & 97.39 \\
\hline
\end{tabular}

It is noticeable a considerable diminishing in losses compared to the original configuration (reduction of $27.78 \%$ without DG and $45.14 \%$ with DG, considering the best configurations in each case). Observing the second configuration without DG and the first one with DG, one can notice that both have the same open switches. In this case, the presence of DG accounted to a loss reduction of $24 \%$.

Improvement of the voltage profile, as a consequence of supplying power near loads, is also a benefit of well-located DG. This effect can be observed in Figure 3.

\section{2-BUS DISTRIBUTION NETWORK}




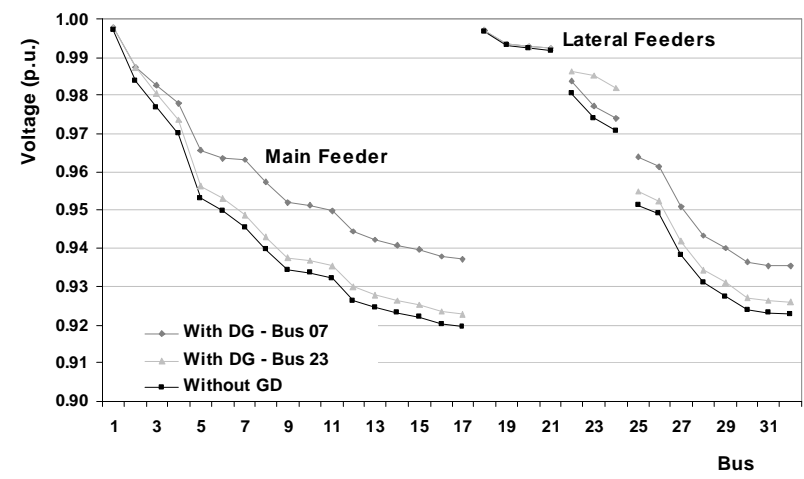

FIGURE 3 - Voltage profile of the initial configuration considering DG in different buses.

Loss allocation results, considering different methodologies, are presented in the simulator for each obtained configuration. Table 3 and Table 4 show the losses allocated for some buses that presented expressive values, considering the original configuration.

TABLE 3 - Loss Allocation for the 32-bus system without Distributed Generation (considering original configuration).

\begin{tabular}{|c|c|c|c|c|}
\hline \multirow{2}{*}{ Bus } & \multicolumn{4}{|c|}{ Loss Allocation Methods (without DG) } \\
\hline & Zbus & SM & MLC & DLC \\
\hline 1 & 0.29 & 0.31 & 0.30 & 0.30 \\
\hline 7 & 10.08 & 10.45 & 10.19 & 10.18 \\
\hline 10 & 2.99 & 3.20 & 3.00 & 3.02 \\
\hline 11 & 3.93 & 4.18 & 3.94 & 3.97 \\
\hline 13 & 9.00 & 9.25 & 8.99 & 9.07 \\
\hline 14 & 3.60 & 3.81 & 3.57 & 3.69 \\
\hline 15 & 3.99 & 4.22 & 3.97 & 4.06 \\
\hline 16 & 4.07 & 4.29 & 4.04 & 4.15 \\
\hline 17 & 6.49 & 6.69 & 6.45 & 6.58 \\
\hline 22 & 1.78 & 1.90 & 1.80 & 1.81 \\
\hline 23 & 10.42 & 9.92 & 10.40 & 10.52 \\
\hline 24 & 11.63 & 10.58 & 11.54 & 11.72 \\
\hline 29 & 32.25 & 28.29 & 31.98 & 37.21 \\
\hline 30 & 10.12 & 10.45 & 10.10 & 9.58 \\
\hline 31 & 14.38 & 14.49 & 14.34 & 13.59 \\
\hline $\begin{array}{c}\text { Total } \\
\text { (32 bus) }\end{array}$ & 176.36 & 176.36 & 176.36 & 180.76 \\
\hline
\end{tabular}

TABLE 4 - Loss Allocation for the 32-bus system with Distributed Generation (considering original configuration).

\begin{tabular}{c||c|c|c||c}
\hline \multirow{2}{*}{\multicolumn{1}{c||}{ Bus }} & \multicolumn{3}{c|}{ Loss Allocation Methods (with DG) } \\
\cline { 2 - 5 } & Zbus & SM & MLC & DLC \\
\hline 1 & 0.24 & 0.26 & 0.25 & 0.25 \\
\hline 7 & 9.40 & 9.89 & 9.52 & 9.54 \\
\hline 10 & 2.83 & 3.09 & 2.85 & 2.87 \\
\hline 11 & 3.72 & 4.03 & 3.73 & 3.77 \\
\hline 13 & 8.59 & 8.97 & 8.58 & 8.68 \\
\hline 14 & 3.40 & 3.66 & 3.38 & 3.51 \\
\hline 15 & 3.79 & 4.07 & 3.77 & 3.88 \\
\hline 16 & 3.87 & 4.15 & 3.84 & 3.96 \\
\hline 17 & 6.18 & 6.48 & 6.14 & 6.29 \\
\hline 22 & 1.24 & 1.33 & 1.27 & 1.27 \\
\hline 23 & -1.96 & -4.18 & -2.26 & -1.60 \\
\hline 24 & 6.92 & 5.55 & 7.02 & 7.02 \\
\hline 29 & 31.57 & 28.08 & 31.26 & 36.16 \\
\hline 30 & 9.61 & 10.09 & 9.60 & 9.12 \\
\hline 31 & 13.67 & 13.98 & 13.65 & 12.94 \\
\hline $\begin{array}{c}\text { Total } \\
\text { (32 bus) }\end{array}$ & $\mathbf{1 5 0 . 5 8}$ & $\mathbf{1 5 0 . 5 8}$ & $\mathbf{1 5 0 . 5 8}$ & $\mathbf{1 5 5 . 3 0}$ \\
\hline & & & &
\end{tabular}

It is noticed that all methods allocate negative losses for buses that have a generator, this means that this power injection contributed to the system, therefore some "incentives" should be given to a well-located generator or consumer.

\section{CONCLUSIONS}

Presented simulator contributes to make faster and easier the analysis and comprehension of distribution networks with distributed generation, regarding reconfiguration and loss allocation. The visual interface gives the user a friendly environment where entering or updating data is quick, and the analysed network is always graphically visible.

Zbus loss allocation method showed an efficient performance, with coherent results and it is simple to understand and implement. Methods SM and MLC require an adjustment factor.

\section{ACKNOWLEDGMENT}

The first author would like to thank Fundação de Amparo a Pesquisa do Estado de São Paulo - FAPESP (Grant 04/04400-4), and Conselho Nacional de Desenvolvimento Científico e Tecnológico - CNPq by their financial support during the development of this research project.

\section{REFERENCES}

[1] D. Shirmohammadi, H. W. Hong, A. Semlyen, and G. X. Luo, 1988, "A compensation-based power flow method for weakly meshed distribution and transmission networks", IEEE Trans. on Power Systems, vol. 3, no. 2, 753-762.

[2] A. J. Conejo, F. D. Galiana, and I. Kockar, 2001, "Z-buss loss allocation", IEEE Trans. on Power Systems, vol. 16, no. $1,105-110$

[3] N. Jenkins, R. Allan, P. Crossley, D. Kirschen, and G. Strbac, 2000, Embedded Generation, IEE Power and Energy Series 31, London, UK, 240-246.

[4] J. Mutale, G. Strbac, S. Curcic, and N. Jenkins, 2000, "Allocation of losses in distribution systems with embedded generation", IEE Proc. - Gen., Trans. and Dist., vol. 147, no. 1, 7-14.

[5] S. K. Goswami and S. K. Basu, 1992, "A new algorithm for the reconfiguration of distribution feeders for loss minimization", IEEE Trans. on Power Delivery, vol. 7, no. 3, 1484-1491. 